\title{
Continuing Challenges in the Medical Management of Gestational Diabetes Mellitus
}

\author{
Authors: \\ Shan Jiang, ${ }^{1}$ Rohit Rajagopal,, *David Simmons ${ }^{1,2}$ \\ 1. Macarthur Diabetes Service, Campbelltown Hospital, Campbelltown, Australia \\ 2. Western Sydney University, Sydney, Australia \\ *Correspondence to Da.Simmons@westernsydney.edu.au \\ Disclosure: $\quad$ Dr Rajagopal reports receiving honoraria for lectures from Novo Nordisk \\ Pharmaceuticals outside the submitted work. The other authors have declared no \\ conflicts of interest.
}

Received: $\quad 06.01 .20$

Accepted: $\quad 15.04 .20$

Keywords: Diabetes, fetal, gestational.

Citation: $\quad$ EMJ Diabet. 2020;DOI/10.33590/emjdiabet/20-00003

\section{Abstract}

The management of gestational diabetes mellitus (GDM) involves screening (or universal testing), a diagnostic oral glucose tolerance test, patient counselling/education, gestational weight management and medical nutrition therapy, and self-monitoring of blood glucose levels with regular glycaemia reviews. This is in addition to pharmacological treatment, often insulin therapy, if glycaemia is above target. Individuals with GDM receive more frequent ultrasound testing to assess fetal growth, and birth is planned and not usually allowed to go much past term. A range of challenges continue to arise in GDM management including screening approaches and diagnostic criteria, dealing with the increasing numbers of individuals diagnosed, weight and glycaemic targets, the long-term safety of oral antihyperglycaemic agents for the offspring, particularly metformin, and adjunct medication for complication prevention. GDM management involves additional complexities including differentiating between those with likely undiagnosed Type 2 diabetes mellitus (diabetes in pregnancy), how to manage patients with high glucose early in pregnancy less than diabetes in pregnancy, and identifying patients with rare causes, for example monogenic diabetes or new Type 1 diabetes mellitus in pregnancy. While the management of GDM has evolved from identifying individuals at high risk of progressing to Type 2 diabetes mellitus, to greater focus on improving pregnancy outcomes, those with prior GDM and their offspring have the highest need for follow-up and prevention strategies. To date, follow-up and intervention remains limited for this high-risk group for both diabetes and cardiovascular disease. Follow-up in these individuals is particularly important for the next pregnancy, especially as GDM prevention from the second trimester onwards remains another continuing challenge.

\section{INTRODUCTION}

Gestational diabetes mellitus (GDM) is hyperglycaemia first detected in pregnancy, short of overt diabetes in pregnancy (DIP). ${ }^{1}$ While some females enter pregnancy with relative

hyperglycaemia, worsening of glycaemic levels usually occurs in the third trimester following increased insulin resistance, secondary to changes in circulating hormones and cytokines that overcome the maximum insulin secretory capacity. ${ }^{2}$ GDM-associated adverse pregnancy 
outcomes for the mother include pre-eclampsia, pregnancy-induced hypertension, increased rates of caesarean section as well as delivery complications associated with neonatal macrosomia. ${ }^{3}$ Adverse neonatal outcomes include babies who are large for gestational age (LGA), birth trauma, shoulder dystocia, prematurity, and neonatal hypoglycaemia. The Pederson hypothesis ${ }^{4}$ proposes that these complications are driven by maternal hyperglycaemia, with glucose crossing the placenta leading to fetal hyperglycaemia and hyperinsulinaemia. Optimal management of GDM decreases the risk of many of these adverse events. ${ }^{5}$ In this article, the authors outline the latest recommendations for the diagnosis of GDM and its medical treatment, with discussion of the supporting evidence and remaining controversies. Prediagnostic GDM prevention is out of the scope of this review.

\section{CHALLENGES IN GESTATIONAL DIABETES MELLITUS SCREENING AND DIAGNOSIS}

Criteria for the diagnosis of GDM have evolved over decades from identifying individuals at long-term risk of developing Type 2 diabetes mellitus, to diagnostic criteria derived from observational studies on the risk of adverse pregnancy outcomes. The landmark Hyperglycaemia and Adverse Pregnancy Outcome (HAPO) Study ${ }^{6}$ heavily influenced the current internationally recommended GDM diagnostic criteria. HAPO was an international, prospective, blinded observational study of 23,316 participants examining the relationship between venous BG concentrations at three timepoints during a $75 \mathrm{~g}$ oral glucose tolerance test (OGTT) undertaken at 24-32 weeks gestation, and the risk of adverse pregnancy outcomes. Primary outcomes were LGA, primary caesarean section, neonatal hypoglycaemia, and high cord C-peptide above the $90^{\text {th }}$ percentile as a surrogate marker for neonatal hyperinsulinaemia. A continuous linear positive relationship was shown between each of the three-timepoint BG concentrations and the primary outcomes. Using these study data, the International Association of Diabetes in Pregnancy Study Groups (IADPSG) formulated the GDM diagnostic thresholds (via consensus) based on an adjusted odds ratio of 1.75 for the primary study adverse pregnancy outcomes.
The IADPSG diagnostic criteria have been adopted by the World Health Organization (WHO), the International Federation of Gynaecology and Obstetrics (FIGO), ${ }^{7}$ the International Diabetes Federation (IDF), 8 and many countries internationally (e.g., the Australasian Diabetes in Pregnancy Society $\left.[A D I P S]^{9}\right)$. However, other approaches to the criteria include the HAPO adjusted odds ratio of 2 for adverse outcomes (used in Canada, for example) ${ }^{10}$ and locally developed criteria (used in England)," while the American Diabetes Association (ADA) ${ }^{12}$ accepts both the American College of Obstetricians and Gynecologists $(A C O G)^{13}$ and IADPSG diagnostic criteria. Moreover, there remains diversity in screening practice to identify those who require an OGTT (if not universal), including risk factor screening and the $50 \mathrm{~g}$ glucose challenge test which misses relative fasting hyperglycaemia, a better correlate of adverse pregnancy outcomes. ${ }^{14}$ Table 1 shows the major criteria for GDM used internationally.

The major justification against the IADPSG criteria is the increase in individuals requiring treatment, putting strain on public health systems, and medicalising more pregnancies. Within Australia, GDM incidence has been reported to increase from a baseline of $9.6 \%$ to $13.0 \%,{ }^{18}$ with a conservative estimated workload increase of up to $31.0 \%{ }^{19}$ while in high-risk populations, such as the United Arab Emirates, over a 4-fold increase in prevalence from $9.2 \%$ to $45.3 \%$ has been reported. ${ }^{20}$ These increases in incidence have been mainly through dropping nonevidence-based screening tests, adding early screening for DIP, only using one positive test for diagnosis (as opposed to the ACOG OGTT criteria requiring two readings above the diagnostic threshold), ${ }^{13}$ a reduction in the fasting glucose cut-off, and including 1-hour glucose criteria. On the other hand, the new criteria capture individuals at increased risk of adverse pregnancy outcomes otherwise missed by alternative OGTT diagnostic criteria, ${ }^{21,}$ 22 and can improve pregnancy outcomes on a population basis with associated health cost savings. ${ }^{23}$ Essentially, work has moved from the delivery room, postnatal ward, and neonatal intensive care unit, to antenatal care including the input of diabetes services. 
Table 1: Major current diagnostic criteria for gestational diabetes mellitus.

\begin{tabular}{|c|c|c|c|c|c|c|}
\hline Criteria & IADPSG/WHO'1,15 & $\begin{array}{l}\text { *ADA/ACOG, } \\
\text { USA }{ }^{12}\end{array}$ & NICE, UK ${ }^{11}$ & ${ }^{*}$ Canada ${ }^{10}$ & $\mathrm{NZSSD}^{16}$ & DIPSI ${ }^{17}$ \\
\hline $\begin{array}{l}\text { Early testing: } \\
\text { when, who, and } \\
\text { test used (all } \\
\text { repeat at } 24-28 \\
\text { weeks if negative) }\end{array}$ & $\begin{array}{l}\text { First antenatal } \\
\text { visit if risk } \\
\text { factors*: FBG, } \\
\text { RBG, HbA1c }\end{array}$ & $\begin{array}{l}\text { First antenatal } \\
\text { visit if risk } \\
\text { factors*: FBG, } \\
\text { RBG, HbA1c }\end{array}$ & $\begin{array}{l}\text { First antenatal } \\
\text { visit if past GDM } \\
75 \mathrm{~g} \text { OGTT }\end{array}$ & $\begin{array}{l}\text { First antenatal } \\
\text { visit if risk } \\
\text { factors*: HbAlc }\end{array}$ & $\begin{array}{l}\text { Universal } \\
\mathrm{HbA1c}<20 \\
\text { weeks GDM } \\
\text { if } \mathrm{HbA1c} \geq 50 \\
\mathrm{mmol} / \mathrm{mol}\end{array}$ & $\begin{array}{l}\text { Universal, } \\
\text { one step, } \\
75 \mathrm{~g} \\
\text { nonfasting }\end{array}$ \\
\hline $\begin{array}{l}\text { Criteria for } \\
\text { proceeding to } \\
\text { OGTT }\end{array}$ & $\begin{array}{l}\text { Usually one } \\
\text { step only }\end{array}$ & $\begin{array}{l}50 \mathrm{~g} \mathrm{GCT} \\
1 \mathrm{HBG} \geq 7.2 \\
\mathrm{mmol} / \mathrm{L}\end{array}$ & $\begin{array}{l}\text { Any of five risk } \\
\text { factors: } \\
\text { - BMI >30 kg/m² } \\
\text { - Previous } \\
\text { macrosomic baby } \\
\text { - Past GDM } \\
\text { - First-degree } \\
\text { relative with } \\
\text { diabetes } \\
\text { - Ethnic minority } \\
\text { with high } \\
\text { prevalence to } \\
\text { diabetes }\end{array}$ & $\begin{array}{l}50 \mathrm{~g} \mathrm{GCT} 1 \mathrm{HBG} \\
\geq 7.8 \mathrm{mmol} / \mathrm{L}\end{array}$ & $\begin{array}{l}50 \mathrm{~g} \mathrm{GCT} \\
1 \mathrm{HBG} \geq 7.8 \\
\mathrm{mmol} / \mathrm{L}\end{array}$ & $\begin{array}{l}\text { Usually one } \\
\text { step only }\end{array}$ \\
\hline Glucose load & $75 \mathrm{~g}$ fasting & $100 \mathrm{~g}$ fasting & $75 \mathrm{~g}$ fasting & $75 \mathrm{~g}$ fasting & $75 \mathrm{~g}$ fasting & $\begin{array}{l}75 \mathrm{~g} \\
\text { nonfasting }\end{array}$ \\
\hline Fasting glucose ${ }^{\dagger}$ & $\geq 5.1 \mathrm{mM}$ & $\geq 5.3 \mathrm{mM}$ & $\geq 5.6 \mathrm{mM}$ & $\geq 5.3 \mathrm{mM}$ & $\geq 5.5 \mathrm{mM}$ & - \\
\hline 1-hour glucose ${ }^{+}$ & $\geq 10.0 \mathrm{mM}$ & $\geq 10.0 \mathrm{mM}$ & - & $\geq 10.6 \mathrm{mM}$ & - & - \\
\hline 2-hour glucose ${ }^{+}$ & $\geq 8.5 \mathrm{mM}$ & $\geq 8.6 \mathrm{mM}$ & $\geq 7.8 \mathrm{mM}$ & $\geq 9.0 \mathrm{mM}$ & $\geq 9.0 \mathrm{mM}$ & $\geq 7.8 \mathrm{mM}$ \\
\hline 3-hour glucose ${ }^{\dagger}$ & - & $\geq 7.8 \mathrm{mM}$ & - & - & - & - \\
\hline $\begin{array}{l}\text { No. of abnormal } \\
\text { tests required }\end{array}$ & 1 & 2 & 1 & 1 & 1 & 1 \\
\hline
\end{tabular}

*Also recommend early screening for diabetes in pregnancy in the presence of risk factors, e.g., previous elevated glucose levels, maternal age $\geq 40$ years, females from high-risk ethnicity groups, family history of diabetes including GDM in a first-degree relative, prepregnancy BMI $\geq 30 \mathrm{~kg} / \mathrm{m}^{2}$, previous macrosomia, polycystic ovarian syndrome, and high-risk medication use (e.g., corticosteroids or antipsychotics). Criteria for (overt) diabetes in pregnancy (unless stated otherwise) are FBG: $\geq 7.0 \mathrm{mmol} / \mathrm{L} ; \mathrm{HbA1c} \geq 6.5 \%$ (47 mmol/mol); RBG: $\geq 11.1 \mathrm{mmol} / \mathrm{L}$.

†Thresholds for diagnosis

ACOG: The American College of Obstetricians and Gynecologists; ADA: The American Diabetes Association; DIPSI: The Diabetes in Pregnancy Study Group India; FBG: fasting blood glucose; GCT: glucose challenge test; GDM: gestational diabetes mellitus; IADPSG: International Association of Diabetes in Pregnancy Study Group; NICE: The National Institute for Health and Care Excellence; NZSSD: The New Zealand Society for the Study of Diabetes; OGTT: oral glucose tolerance test; RBG: random blood glucose; WHO: World Health Organization; 1HBG: 1-hour blood glucose.

Further rationale limiting uptake of the new GDM criteria is that they are predominantly based on one observational study classified by the WHO as 'weak evidence'15 and that there have been no randomised controlled trials (RCT) of treatment using these criteria (a criticism which can be applied to most GDM criteria). In the interim, new models of care are now being introduced to deal 
with the larger numbers of patients, for example use of a risk-based step-up or step-down approach to more intensive management. ${ }^{24}$

Up to $1.8 \%$ of individuals with GDM have undiagnosed monogenic diabetes, particularly with glucokinase mutations (maturity onset diabetes of the young [MODY 2]). ${ }^{25}$ Individuals with MODY 2 have a high fasting glucose but often a normal postload glucose, hence are readily identified with an OGTT rather than GCT. If the baby also has the mutation for MODY 2, then managing maternal glycaemia to current maternal glucose targets can result in a baby who is small for gestational age (SGA). Approaches to systematically identify those with MODY 2, including risk calculators and clinical genetic assessment, are becoming increasingly widespread but still require clinical recognition to initiate the process.

The current issues with diagnosing GDM clearly remain an area of debate. There is a need to balance the overarching requirement or global consensus on a single set of criteria and the strength of evidence for the diagnostic threshold with the practicality of their implementation in large populations. A further complication is the impact of early GDM screening and the uncertainty over the criteria for GDM before 20 weeks gestation.

\section{IS THERE A ROLE FOR EARLY GESTATIONAL DIABETES MELLITUS SCREENING?}

The IADPSG GDM diagnostic criteria are based on HAPO 24-32-week gestational data. However, screening for DIP early in pregnancy prior to 24 weeks gestation is also recommended among individuals with risk factors (see Table 1) to identify those with undiagnosed Type 2 diabetes mellitus. The diagnostic thresholds for DIP are the same as the criteria for Type 2 diabetes mellitus (fasting glucose $\geq 7.0 \mathrm{mmol} / \mathrm{L}, 2$ hour glucose or random glucose $\geq 11.1 \mathrm{mmol} / \mathrm{L}$, and/or $\mathrm{HbA} 1 \mathrm{c}$ $\geq 6.5 \%$ [47 mmol$/ \mathrm{mol}])^{9}$

While seeking individuals with DIP at the earliest opportunity, a group with milder forms of hyperglycaemia in pregnancy, early GDM, are inevitably identified and it remains unclear how best to diagnose (especially as 'normal' glucose levels vary with gestational week) and manage these individuals. ${ }^{26}$ Patients fulfilling the IADPSG criteria in early pregnancy show characteristics of metabolic syndrome, ${ }^{27}$ and a systematic review using different criteria in mostly observational studies has shown that individuals with early diagnosed GDM, despite treatment, had higher perinatal mortality, neonatal hypoglycaemia, and insulin use compared to those diagnosed in later pregnancy. ${ }^{28}$ Showing greater adverse outcomes does not mean that improved treatment will effectively reduce risk. A definitive multicentre RCT, the Treatment of BOoking Gestational diabetes Mellitus (ToBOGM) Study, ${ }^{29,30}$ is currently underway, evaluating the outcomes of treatment of individuals diagnosed with early GDM ( $<20$ weeks gestation) versus delayed treatment until after a confirmatory OGTT at 24 weeks gestation. The results of the small pilot study ${ }^{29}$ demonstrated an increased risk of neonatal intensive care unit admission in the early treatment arm (mainly due to SGA), but an increase in LGA in the nontreatment arm. This highlights the complexity of this issue and the need for high quality interventional studies to evaluate the safety and efficacy of the guideline recommendations. In the interim, and until the release of the ToBOGM results, the systematic review of current evidence ${ }^{28}$ recommended a fasting glucose of $6.1-6.9 \mathrm{mmol} / \mathrm{L}$ be used to diagnose early GDM.

\section{ARE THE APPROPRIATE GESTATIONAL DIABETES MELLITUS TREATMENT TARGETS AVAILABLE?}

\section{Glycaemic Management Targets}

There is no worldwide consensus on the GDM treatment targets. Generally, patients are recommended to self-monitor finger prick BG four times a day: fasting and postprandial levels using targets are shown in Table 2.

The Australian Carbohydrate Intolerance Study in Pregnant Females (ACHOIS) ${ }^{31}$ RCT showed a reduction in the primary perinatal composite outcome consisting of neonatal death, shoulder dystocia, bone fracture, and nerve palsy, when individuals with GDM (defined by $75 \mathrm{~g}$ OGTT criteria of fasting $B G<7.8 \mathrm{mmmol} / \mathrm{L}$ and $a$ 2-hour BG 7.8-11.0 $\mathrm{mmol} / \mathrm{L}$ ) were treated to the target of fasting $B G \leq 5.5 \mathrm{mmol} / \mathrm{L}$, and 2 hours postprandial $B G \leq 7.0 \mathrm{mmol} / \mathrm{L}$. 
Table 2: Treatment target recommendations for gestational diabetes mellitus.

\begin{tabular}{|l|l|l|l|}
\hline & ADIPS & ACHOIS & MFMUN $^{32}$ \\
\hline Fasting & $\leq 5.0 \mathrm{mmol} / \mathrm{L}$ & $\leq 5.5 \mathrm{mmol} / \mathrm{L}$ & $<5.3 \mathrm{mmol} / \mathrm{L}$ \\
\hline $\mathbf{1}$ hour postprandial & $\leq 7.4 \mathrm{mmol} / \mathrm{L}$ & $\mathrm{N} / \mathrm{A}$ & $\mathrm{N} / \mathrm{A}$ \\
\hline $\mathbf{2}$ hours postprandial & $\leq 6.7 \mathrm{mmol} / \mathrm{L}$ & $\leq 7.0 \mathrm{mmol} / \mathrm{L}$ & $<6.7 \mathrm{mmol} / \mathrm{L}$ \\
\hline $\begin{array}{l}\text { Number of abnormal results } \\
\text { for insulin therapy }\end{array}$ & $\begin{array}{l}\geq \text { two elevated levels at a } \\
\text { given testing time within 1 } \\
\text { week }\end{array}$ & $\begin{array}{l}\text { ztwo elevated levels at any } \\
\text { testing time or one elevated } \\
\text { level } \geq 9 \text { mmol/L within a } \\
\text { 2-week period }\end{array}$ & $\begin{array}{l}\text { Majority of fasting values or } \\
\text { postudy visits were elevated } \\
\text { studial values between }\end{array}$ \\
\hline Basis & $\begin{array}{l}\text { 2 standard deviations above } \\
\text { the mean of glucose levels } \\
\text { of pregnant females without } \\
\text { GDM from the HAPO study }\end{array}$ & $\begin{array}{l}\text { Australian Carbohydrate } \\
\text { Intolerance Study in } \\
\text { Pregnant Females }\end{array}$ & $\begin{array}{l}\text { Maternal and Fetal Medicine } \\
\text { Units Network randomised } \\
\text { trial of Treatment for Mild } \\
\text { Gestational Diabetes }\end{array}$ \\
\hline
\end{tabular}

ACHOIS: Australian Carbohydrate Intolerance Study in Pregnant Women; ADIPS: Australasian Diabetes in Pregnancy Society; GDM: gestational diabetes mellitus; HAPO: Hyperglycemia and Adverse Pregnancy Outcome; MFMUN: Maternal and Fetal Medicine Units Network.

The second major RCT, conducted by the Maternal-Fetal Medicine Units Network (MFMUN) ${ }^{32}$ demonstrated that an even tighter glycaemic target of fasting $B G<5.3 \mathrm{mmol} / \mathrm{L}$ and 2 hours postprandial BG $<6.7 \mathrm{mmol} / \mathrm{L}$ was associated with a significantly decreased risk of LGA, shoulder dystocia, caesarean section, gestational hypertension, and pre-eclampsia in individuals with GDM diagnosed using the following criteria: fasting $B G<5.3 \mathrm{mmol} / \mathrm{L}$, and two or three timed glucose results exceeding the levels of 1 hour $10.0 \mathrm{mmol} / \mathrm{L}, 2$ hours $8.6 \mathrm{mmol} / \mathrm{L}$, 3 hours $7.8 \mathrm{mmol} / \mathrm{L}$ on a $100 \mathrm{~g} 3$ hour OGTT. Retrospective cohort studies, by Bogdanet $D$ et al. $^{33}$ for example, have found that in GDM, patients treated to a target of fasting $B G \leq 5.0$ $\mathrm{mmol} / \mathrm{L}$ and 1-hour postprandial $\mathrm{BG} \leq 7.0 \mathrm{mmol} / \mathrm{L}$, there was a similar rate of LGA and SGA as those without GDM. RCT of different glycaemic thresholds, among individuals diagnosed using the IADPSG criteria, are now needed to identify treatment strategies that result in a reduction in fetal adiposity and hyperinsulinaemia and their associated sequelae, without increasing the risk of SGA babies and intrauterine undernutrition.

\section{GESTATIONAL WEIGHT GAIN TARGETS}

Gestational weight management is important in individuals with GDM, with targets based on the Institute of Medicine (IOM) guidelines ${ }^{34}$ (Table 3). These are based on the effect of gestational weight gain/loss on a series of maternal and fetal outcomes. Individuals who are overweight or obese in the first trimester are not expected to gain weight. Individuals with GDM and gestational weight gain above the recommendations have increased risk of LGA, preterm delivery, and primary caesarean section. ${ }^{35}$

Recent debate has largely centred upon whether gestational weight gain among individuals who are obese should remain between 0-5 kg (i.e., loss of maternal body weight after accounting for pregnancy-related weight gain attributable to baby, placenta, breasts). Such negative weight balance might decrease fetal fat mass, but also reduce fetal lean mass with potential long term sequelae (e.g., hypertension, heart disease). ${ }^{36}$

\section{HOW SHOULD GESTATIONAL DIABETES MELLITUS BE TREATED?}

\section{Diet}

Lifestyle interventions, including medical nutrition therapy and physical activity promotion, are the cornerstone of GDM treatment and for limiting excessive gestational weight gain. ${ }^{37}$ 
Table 3: Recommended Gestational Weight Gain in Pregnancy.

\begin{tabular}{|l|l|l|}
\hline Prepregnancy BMI $\left(\mathrm{kg} / \mathrm{m}^{2}\right)$ & Total weight gain $(\mathrm{kg})$ & $\begin{array}{l}\text { Rate of weight gain in second and third } \\
\text { trimester (mean [range] } \mathrm{kg} / \mathrm{week})\end{array}$ \\
\hline Underweight (<18.5) & $12.5-18.0$ & $0.51(0.44-0.58)$ \\
\hline Normal weight (18.5-24.9) & $11.5-16.0$ & $0.42(0.35-0.50)$ \\
\hline Overweight (25.0-29.9) & $7.0-11.5$ & $0.28(0.23-0.33)$ \\
\hline Obese ( $\geq 30.0)$ & $5.0-9.0$ & $0.22(0.17-0.27)$ \\
\hline
\end{tabular}

Medical nutrition therapy involves a dietary assessment and tailored recommendations to balance sufficient micro- and macronutrients for maternal wellbeing and fetal growth, without excessive carbohydrate or fat intake, and avoiding excessive gestational weight gain. The Dietary Reference Intakes for pregnancy recommend a minimum of $175 \mathrm{~g}$ of carbohydrate, $71 \mathrm{~g}$ of protein, and $28 \mathrm{~g}$ of fibre per day with refinements based on the individual's biometric measurements. ${ }^{38}$ A diet consisting of 1,384$1,863 \mathrm{kcal} /$ day did not impact on pregnancy outcomes in individuals with GDM, while an intake of 1,560-1,630 kcal/day may assist in limiting gestational weight gain in those with GDM with pregestational obesity, without adverse effect. ${ }^{39}$ Low-carbohydrate diets may be associated with an increase in insulin resistance and, paradoxically, a higher fasting glucose. ${ }^{40}$

Apart from the Dietary Approaches to Stop Hypertension (DASH) diet rich in fruits, vegetables, whole grains, and low-fat dairy products, which has been shown in GDM to decrease fasting and postprandial glucose levels with concomitant outcomes of decreased medication use, decreased macrosomia, and decreased rate of caesarean sections, there are no specific types of dietary composition that have been identified via RCT to be superior for individuals with GDM. ${ }^{41}$ A low glycaemic index diet decreases fasting and postprandial glucose levels as well as the need for insulin use, but without consistent improvements in pregnancy

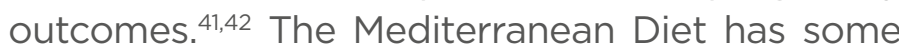
evidence for decreasing LGA babies without a rise in SGA delivery. ${ }^{43}$ In terms of meal frequency, the American Academy of Nutrition and Dietetics currently recommends, via consensus, a distribution of nutritional intake via three main meals and two or more snacks to assist with reducing postprandial glucose rise. ${ }^{39}$

\section{Exercise}

An exercise regimen consisting of at least 20-30 minutes per day of moderate-intensity exercise on most days of the week is recommended for individuals with GDM. ${ }^{38}$ Both moderate-intensity aerobic and resistance exercise have been shown to lower fasting and postprandial glucose levels in GDM (with no reduction in insulin requirement). ${ }^{44}$ Patients with GDM provided with exercise intervention have been found to have decreased gestational weight gain, macrosomia, caesarean section, preterm birth, and SGA. ${ }^{45,46}$ There is emerging evidence that sedentary behaviour (any waking behaviour characterised by an energy expenditure $\leq 1.5$ metabolic equivalents while in a sitting or reclining posture) confers up to 3.8 odds ratio for adverse neonatal outcomes in GDM pregnancy. ${ }^{47}$ Therefore, advice should include recommendations for both active exercise and a decrease in sedentary behaviour.

\section{Medication}

\section{Insulin}

Insulin therapy in combination with lifestyle interventions to reach glycaemic targets reduces adverse pregnancy outcomes related to GDM in major RCT.31,32 The flexibility of insulin use allows for dose titration to reach glycaemic targets and tailoring to the timing of hyperglycaemia, such as exclusive postprandial hyperglycaemia or fasting hyperglycaemia. Use of the long-acting insulin detemir in pregnancy 
is noninferior to isophane insulin with regard to efficacy and perinatal outcome. No RCT of glargine have been conducted. Quick-acting insulin analogues such as aspart or lispro, injected approximately 15-20 minutes prior to a meal, can effectively reduce the postprandial peak in glucose level, whilst having similar safety profiles to human insulin, including minimal formation of insulin-antibody complexes. ${ }^{48}$

\section{Metformin}

Oral medications address some of the practical issues relating to insulin administration, leading to higher acceptability amongst pregnant patients. ${ }^{49}$ Metformin is the most common oral medication used for GDM. Compared to insulin use, metformin has been shown to result in less maternal gestational weight gain, lower postprandial glucose level, less pregnancyinduced hypertension, and less severe neonatal hypoglycaemia. ${ }^{50}$ Metformin use is associated with its typical adverse effects (abdominal pain and diarrhoea), as well as more spontaneous preterm delivery without an increase in other prematurity-associated complications. ${ }^{49}$ Metformin therapy may require supplemental insulin therapy in $26.8-33.8 \%$ of individuals. ${ }^{50}$ No short-term adverse fetal outcomes, including fetal malformations, have been described in GDM. ${ }^{49}$ However, the long-term effects of metformin on offspring remain uncertain. ${ }^{51}$ The MiG-TOFU 2-year follow-up ${ }^{52}$ and the MiG-TOFU 7-9-year follow-up ${ }^{53}$ showed differences in offspring adiposity, and studies outside of GDM have been associated with raised offspring blood pressure and fasting glucose. Further follow-up studies are needed.

\section{Glibenclamide}

Glibenclamide is no longer recommended and is associated with higher fetal birth weight and macrosomia rate compared to both insulin or metformin use, more neonatal hypoglycaemia compared to insulin use, and more maternal gestational weight gain compared to metformin use. $^{50}$ A plausible explanation for this adverse outcome profile may be related to the placental transfer of the medication leading to fetal hyperinsulinaemia. ${ }^{50}$

\section{CHALLENGES IN OBSTETRIC MONITORING}

Ultrasound monitoring allows detection of fetal malformations, fetal movements, placental insufficiency, and SGA, which may be a reflection of overtreatment of GDM, while LGA or polyhydramnios may suggest suboptimal glycaemic control. Individuals with GDM often have a growth scan performed at approximately the $32^{\text {nd }}$ week of pregnancy, as an increase in the fetal abdominal circumference to $>90^{\text {th }}$ centile on ultrasound at this time is associated with an increased rate of macrosomia, caesarean section, and shoulder dystocia. ${ }^{54}$ However, there is a suggestion that an earlier growth scan at the $28^{\text {th }}$ week of gestation may be required to detect increased abdominal circumference sufficiently early for glycaemic management to result in a reduction in adverse neonatal outcomes. ${ }^{55}$ Antenatal steroid treatment at 37-39 weeks gestation for lung maturation prior to elective caesarean section has recently been shown in a case control study to be associated with increased neonatal hypoglycaemia with no evidence of reduced neonatal respiratory problems, and is another aspect of care warranting an RCT. ${ }^{56}$ As a pregnancy at high risk of pre-eclampsia, aspirin may be indicated; however, trials to date have only included limited numbers of individuals with GDM.

\section{CHALLENGES IN POSTPARTUM MANAGEMENT}

Individuals with GDM are at increased risk of developing GDM in future pregnancies as well as an increased lifetime risk of cardiovascular disease $\mathrm{e}^{57}$ and Type 2 diabetes mellitus, including by the time of the next pregnancy (and with it, the risk of fetal malformations). In the HAPO follow-up study, 52.2\% of females with GDM according to IADPSG criteria developed either a prediabetes state or Type 2 diabetes in the median 11.4 years of follow-up. ${ }^{58}$ For individuals with DIP, 59\% are diagnosed with either a prediabetes state or Type 2 diabetes mellitus at the 6-8 week postpartum OGTT. ${ }^{59}$ Progression to Type 2 diabetes mellitus can be reduced by up to $50 \%$ among patients with prior GDM. ${ }^{60}$ In spite of this evidence, wide-scale systematic follow-up programmes remain underdeveloped. There are 
currently no evidence-based guidelines for the frequency of postpartum follow up of patients who have had GDM, though organisations such as ADIPS have released recommendations: ${ }^{9}$

\section{> Postpartum $75 \mathrm{~g}$ OGTT at 6-8} weeks postpartum

>Annual $75 \mathrm{~g}$ OGTT if the individual is planning future pregnancy

> In those not planning pregnancy, screening via 75 g OGTT every 3 years, with increase in frequency based on clinical circumstances

> Where OGTT is not feasible, HbAlc can be used but has low sensitivity for impaired glucose tolerance

\section{CONCLUSION}

The management of GDM has evolved over the years to focus on evidence-based strategies proven to be safe and efficacious in diagnosis, monitoring, and treatment, aiming to improve maternal and fetal outcomes. Though the finer details may not be uniform across the world, the basic structure of management is consistent as a global practice. However, underneath this relative consistency, a range of GDM-related practices continue to vary globally including screening approaches and diagnostic criteria, dealing with the increasing numbers of individuals diagnosed, weight and glycaemic targets, the use of oral antihyperglycaemic agents, and schedule for postpartum follow-up.

\section{References}

1. International Association of Diabetes and Pregnancy Study Groups Consensus Panel. International association of diabetes and pregnancy study groups recommendations on the diagnosis and classification of hyperglycemia in pregnancy. Diabetes Care. 2010;33(3):676-82.

2. Catalano PM. Obesity, insulin resistance, and pregnancy outcome. Reproduction. 2010;140(3):365-71.

3. Simmons D. Diabetes and obesity in pregnancy. Best Pract Res Clin Obstet Gynaecol. 2011;25(1):25-36.

4. Pedersen J. Weight and length at birth of infants of diabetic mothers. Acta Endocrinologica (Copenh). 1954;16(4):330-42.

5. Farrar D et al. Treatments for gestational diabetes: a systematic review and meta-analysis. BMJ Open 2017;7(6):e015557.

6. The HAPO Study Cooperative Research Group. Hyperglycemia and Adverse Pregnancy Outcomes. N Engl J Med. 2008;358(19):1991-2002.

7. Hod $M$ et al. The International Federation of Gynecology and Obstetrics (FIGO) Initiative on gestational diabetes mellitus: a pragmatic guide for diagnosis, management, and care. Int J Gynaecol Obstet. 2015;131 (Suppl 3):S173-211.

8. International Diabetes Federation Implementation Protocol. Guidelines for Healthcare Professionals. 2015. Available at: https://www.idf. org/e-library/guidelines/77-idf-gdmmodel-of-care-implementation- protocol-guidelines-for-healthcareprofessionals.html. Date accessed: 10 June 2020

9. Nankervis A et al.; The Australasian Diabetes in Pregnancy Society. ADIPS consensus guidelines for the testing and diagnosis of gestational diabetes mellitus in Australia. 2013. Available at: http://www.adips.org/downloads/ ADIPSConsensusGuidelinesGDM03.05.13VersionACCEPTEDFINAL.pdf. Date accessed: 10 June 2020

10. Feig DS et al. 2018 Clinical Practice Guidelines: Diabetes and Pregnancy. Can J Diabetes. 2018;42:S255-82.

11. Webber $\mathrm{J}$ et al. Diabetes in pregnancy: management of diabetes and its complications from preconception to the postnatal period (NG3). Br J Diabetes Vasc Dis. 2015; 15:107-11

12. Classification and Diagnosis of Diabetes: Standards of Medical Care in Diabetes-2020. Diabetes Care. 2020;43(Suppl 1):S14-31.

13. ACOG Practice Bulletin No. 190: Gestational Diabetes Mellitus. Obstet and Gynecol. 2018;131(2):e49-64.

14. Simmons D, Moses RG. Gestational diabetes mellitus: to screen or not to screen?: Is this really still a question? Diabetes Care. 2013;36(10):2877-8.

15. World Health Organization (WHO). Diagnostic criteria and classification of hyperglycaemia first detected in pregnancy. 2013. Available at: https:// www.who.int/diabetes/publications/ Hyperglycaemia_In_Pregnancy/en/. Date accessed: 11 June 2020

16. Ministry of Health - Manatū Hauora. Screening, Diagnosis and
Management of Gestational Diabetes in New Zealand: A clinical practice guideline. Available at: https://www. health.govt.nz/publication/screeningdiagnosis-and-managementgestational-diabetes-new-zealandclinical-practice-guideline. Last accessed: 11 June 2020 .

17. Seshiah $\vee$ et al. Gestational diabetes mellitus - guidelines. J Assoc Physicians India. 2006;54:622-8.

18. Moses RG et al. The impact of potential new diagnostic criteria on the prevalence of gestational diabetes mellitus in Australia. Med J Aust. 2011;194(7):338-40.

19. Flack JR et al. Recommended changes to diagnostic criteria for gestational diabetes: impact on workload. Aust N Z J Obstet Gynaecol. 2010;50(5):439-43.

20. Agarwal MM et al. Gestational diabetes: differences between the current international diagnostic criteria and implications of switching to IADPSG. J Diabetes Complications. 2015;29(4):544-9.

21. Jiang $\mathrm{S}$ et al. Comparison of adverse pregnancy outcomes based on the new IADPSG 2010 gestational diabetes criteria and maternal body mass index. Aust N Z J Obstet Gynaecol. 2017;57(5):533-9.

22. Meek $C L$ et al. Diagnosis of gestational diabetes mellitus: falling through the net. Diabetologia. 2015;58(9):2003-12.

23. Duran A et al. Introduction of IADPSG Criteria for the Screening and Diagnosis of Gestational Diabetes Mellitus Results in Improved 
Pregnancy Outcomes at a Lower Cost in a Large Cohort of Pregnant Women: The St. Carlos Gestational Diabetes Study. Diabetes Care. 2014;37(9):2442-50

24. Sina $M$ et al. Antenatal models of care for women with gestational diabetes mellitus: Vignettes from an international meeting. Aust $\mathrm{N} Z \mathrm{~J}$ Obstet Gynaecol. 2020. doi: 10.1111/ ajo.13144. [Epub ahead of print].

25. Misra S, Dornhorst A. Gestational diabetes mellitus: primum non nocere Diabetes Care. 2012:35(9):1811-3.

26. Wexler DJ et al. Research gaps in gestational diabetes mellitus: executive summary of a national institute of diabetes and digestive and kidney workshop. Obstet Gynecol. 2018;132(2):496-505.

27. Harreiter $\mathrm{J}$ et al. IADPSG and WHO 2013 gestational diabetes mellitus criteria identify obese women with marked insulin resistance in early pregnancy. Diabetes Care. 2016;39(7):e90-e2.

28. Immanuel J, Simmons D. Screening and treatment for early-onset gestational diabetes mellitus: a systematic review and meta-analysis. Curr Diab Rep. 2017;17(11):115.

29. Simmons $D$ et al. The treatment of booking gestational diabetes mellitus (TOBOGM) pilot randomised controlled trial. BMC Pregnancy and Childbirth. 2018;18(151)

30. Simmons D et al. Hyperglycaemia in early pregnancy: the Treatment of Booking Gestational diabetes Mellitus (TOBOGM) study. A randomised controlled trial. Med J Aust. 2018;209(9):405-6.

31. Crowther CA et al. Effect of treatment of gestational diabetes mellitus on pregnancy outcomes. $\mathrm{N}$ Engl J Med. 2005;352:2477-86.

32. Landon $M B$ et al. A multicenter, randomized trial of treatment for mild gestational diabetes. $\mathrm{N}$ Engl J Med. 2009;361:1339-48

33. Bogdanet D et al. ATLANTIC DIP insulin therapy for women with IADPSG-diagnosed gestationa diabetes mellitus. Does it work? J Clin Endocrinol Metab. 2017:102(3):849-57.

34. Rasmussen KM, Yaktine AL, (eds.), Weight Gain During Pregnancy: Reexamining the Guidelines (2009) $1^{\text {st }}$ edition, Washington DC: The National Academies Press.

35. Cheng YW et al. Gestational weight gain and gestational diabetes mellitus: perinatal outcomes. Obstet Gynecol. 2008;112(5):1015-22.

36. Catalano PM et al. Inadequate weight gain in overweight and obese pregnant women: what is the effect on fetal growth? Am J Obstet Gynecol. 2014:211(2):137.e1-7.
37. Cochrane Database of Systematic Reviews. Lifestyle interventions for the treatment of women with gestational diabetes. 2017. Available at: https://www.cochranelibrary.com/ cdsr/doi/10.1002/14651858.CD011970. pub2/full. Last accessed: 11 June 2020.

38. 14. Management of diabetes in pregnancy: standards of medical care in diabetes - 2019. Diabetes Care. 2019;42(Suppl 1):S165-72.

39. Duarte-Gardea MO et al. Academy of Nutrition and Dietetics Gestational Diabetes Evidence-Based Nutrition Practice Guideline. J Acad Nutr Diet. 2018;188(9):1719-42.

40. Hernandez TL et al. Women with gestational diabetes mellitus randomized to a higher-complex carbohydrate/low-fat diet manifest lower adipose tissue insulin resistance, inflammation, glucose, and free fatty acids: a pilot study. Diabetes Care. 2016;39(1):39-42.

41. Yamamoto JM et al. Gestational diabetes mellitus and diet: a systematic review and metaanalysis of randomized controlled trials examining the impact of modified dietary interventions on maternal glucose control and neonatal birth weight. Diabetes Care. 2018;41(7):1346-61

42. Viana LV et al. Dietary intervention in patients with gestational diabetes mellitus: a systematic review and meta-analysis of randomized clinical trials on maternal and newborn outcomes. Diabetes Care. 2014;37(12):3345-55.

43. Assaf-Balut $C$ et al. A Mediterranean diet with additional extra virgin olive oil and pistachios reduces the incidence of gestational diabetes mellitus (GDM): a randomized controlled trial: The St. Carlos GDM Prevention Study. PLoS One. 2017;12(10):e0185873.

44. Harrison $A L$ et al. Exercise improves glycaemic control in women diagnosed with gestational diabetes mellitus: a systematic review. $J$ Physiother. 2016;62(4):188-96.

45. Wang $C$ et al. Exercise intervention during pregnancy can be used to manage weight gain and improve pregnancy outcomes in women with gestational diabetes mellitus. BMC Pregnancy Childbirth. 2015;15:255.

46. Barakat $\mathrm{R}$ et al. Exercise during pregnancy and gestational diabetesrelated adverse effects: a randomised controlled trial. Br J Sports Med. 2013:47(10):630-6.

47. Anjana RM et al. Physical activity patterns and gestational diabetes outcomes - The Wings Project. Diabetes Res Clin Pract. 2016;116:253-62.
48. Simmons D. Safety considerations with pharmacological treatment of gestational diabetes mellitus. Drug Saf. 2015;38(1):65-78.

49. Rowan JA et al. Metformin versus insulin for the treatment of gestational diabetes. N Engl J Med. 2008;358:2003-15.

50. Balsells $M$ et al. Glibenclamide, metformin, and insulin for the treatment of gestational diabetes: a systematic review and meta-analysis. BMJ. 2015;350:h102.

51. Lindsay RS, Loeken MR. Metformin use in pregnancy: promises and uncertainties. Diabetologia. 2017;60(9):1612-9.

52. Rowan JA et al. Metformin in Gestational Diabetes: The Offspring Follow-Up (MiG TOFU). Body composition at 2 years of age. 2011;34(10):2279-84

53. Rowan JA et al. Metformin in gestational diabetes: the offspring follow-up (MiG TOFU): body composition and metabolic outcomes at 7-9 years of age. BMJ Open Diabetes Res Care. 2018;6(1):e000456.

54. Bochner CJ et al. Early third-trimester ultrasound screening in gestational diabetes to determine the risk of macrosomia and labor dystocia at term. Am J Obstet Gynecol. 1987;157(3):703-8.

55. Rossi G et al. Adequate timing of fetal ultrasound to guide metabolic therapy in mild gestational diabetes mellitus. Results from a randomized study. Acta Obstet Gynecol Scand. 2000;79(8):649-54

56. Gupta K et al. Complications of antenatal corticosteroids in infants born by early term scheduled cesarean section. Diabetes Care. 2020:dc192126.

57. Kramer CK et al. Gestational diabetes and the risk of cardiovascular disease in women: a systematic review and meta-analysis. Diabetologia. 2019:62(6):905-14

58. Lowe WL et al. Association of gestational diabetes with maternal disorders of glucose metabolism and childhood adiposity. JAMA. 2018:320(10):1005-16.

59. Wong $T$ et al. The clinical significance of overt diabetes in pregnancy. Diabetic Med. 2013;30(4):68-74.

60. Ratner RE et al. Prevention of diabetes in women with a history of gestational diabetes: effects of metformin and lifestyle interventions. $\mathrm{J}$ Clin Endocrinol Metab. 2008:93(12):4774-9. 